\title{
Intelligent Climate Control System inside a Greenhouse
}

\author{
A. Labidi ${ }^{1}$, A. Chouchaine ${ }^{2}$, A. Mami $^{3}$ \\ University of Tunis El Manar, Faculty of Science, UR 17ES11 LAPER, 2092 Tunis, Tunisia
}

\begin{abstract}
An agricultural greenhouse is an environment to ensure intensive agricultural production. The favorable climatological conditions (temperature, lighting, humidity ...) for agricultural production must be reproduced in a non-natural way by controlling these parameters using several actuators (heating/air conditioning, ventilation, and humidifier/ dehumidifier). The objective of this study is to control the humidity inside the greenhouse; it is a problem that remains to be negotiated. To that end, an actuator based on a humidifier and a dehumidifier was installed in an experimental greenhouse and activated by a fuzzy logic controller to achieve the desired optimal indoor humidity in the greenhouse.
\end{abstract}

Keywords-Greenhouse; climate; humidity; fuzzy logic controller; humidification; dehumidification

\section{INTRODUCTION}

A greenhouse is intended to protect plants and promote greenhouse production by creating climatic conditions that are more favorable than the local climate. Therefore, the regulation of the indoor climate, in particular the relative humidity, is necessary to create an ideal environment for plant growth. Greenhouse climate management is controlled by different actuators: ventilation, heating, humidification, and dehumidification system. Many different sensors can measure the actual climate conditions for a precise real-time control method. The need to improve these climatic conditions has called for advanced control algorithms due to the complexity and nonlinearity of the greenhouse system. Many researchers have developed several control strategies to improve the indoor microclimate such as Proportional - Integral Derivative controller (PID controller) [1], Neural Network $[2,3]$, the PI controller (SSODPI and PI-SSOD event controllers) [4], Adaptive Neuro-fuzzy controller [5,6,7,8], Genetic algorithm [9], Optimal control [10], Predictive Neural Control [11], four control techniques have been developed [12]: Adaptive Neuro-Fuzzy Control (ANFIS), Fuzzy Logic Control (FLC), PI Control and Artificial Neural Network Control (ANN), to adjust the temperature inside the greenhouse, and a Fuzzy Logic Controller (FLC) [13,14] which is a valuable element in the control of hardly identifiable and non-linear systems. Also, several studies have established the importance and usefulness of the FLC controller and its tool to solve the problem of complexity and non-linearity of the greenhouse system [15] from which presented a comparative study of a basic fuzzy controller and optimized fuzzy controllers to show their advantages and disadvantages. The author in [16] have developed a fuzzy modeling application to control the indoor air temperature of a MISO greenhouse, [17] have used this application with a new approach that automatically organizes a fuzzy flat system into a hierarchical collaborative architecture, this architecture adapted to transfer the information contained in the fuzzy rule sets to another fuzzy subsystem.

In this paper, an FLC is developed to manage humidity combined with a humidifier and a dehumidifier to ensure the optimization of the microclimate. The importance of this work comes from the fact that humidity is the most difficult environmental factor to control in an agricultural greenhouse, and whether the humidity level is too high or too low; the loss of quality decreases the selling price of the crops and increases the production costs, thus reducing profits. This work is organized as follows; the second section deals with a description of the experimental set-up studied with the measuring equipment followed by dynamic modeling of the greenhouse's internal moisture behaviors. The third section describes the Fuzzy Logic Controller strategy that was developed and applied to the greenhouse to improve the humidity inside the greenhouse. In the fourth section, a presentation of the results is given followed by a discussion. Finally, this study will be complemented by a general conclusion.

\section{DyNAmiC MOdEl OF THE Agricultural GREENHOUSE}

\section{A. Greenhouse Modeling}

The dynamic modeling of the agricultural greenhouse presents the balance of energy and mass exchanges inside the microclimate. The study of such a model can be useful to observe the actuator's influence on the system's behavior containing two differential equations describing the energy balance of the indoor humidity and the indoor air temperature. According to the law of energy conservation, the equations describing the heat balance of the indoor air can be obtained from the following equation [18].

$C_{z} \frac{d T_{\text {in }}(t)}{d t}=\left(Q^{\text {Solar radiation }}+Q^{\text {ht, cover }}+Q^{\text {ht, ground }}+\right.$
$\left.Q^{\text {Heaters }}+Q^{\text {Humidifying }}+Q^{\text {ventilation }}\right)$

With :

$C_{z}$ : The thermal capacity of the air (product of air specific thermal capacity, air density and greenhouse volume) and all other elements thermal equilibrium with the air.

- $Q^{\text {Solar radiation }}$ : heat gain by solar radiation $\left(\mathrm{Wm}^{-2}\right)$.

- $Q^{\text {ht,coverture }}$ : heat transfer from the envelope between the inside and outside of the greenhouse [19]. $\left(\mathrm{Wm}^{-2}\right)$. 
- $Q^{\text {ht,ground }}$ : heat transfer to the ground $\left(\mathrm{Wm}^{-2}\right)$.

- $Q^{\text {Heaters }}$ : the heat gain of the heating system $\left(W^{-2}\right)$.

- $Q^{\text {Humidifying }}:$ the cooling effect of the humidification $\operatorname{system}\left(W m^{-2}\right)$.

- $Q^{\text {Ventilation }}:$ heat loss due to ventilation $\left(W^{-2}\right)$ $[20,21]$.

Indoor air is also characterized by its relative humidity. The indoor humidity equation can be expressed by:

$\frac{d H i n}{d t}=$

$H^{\text {Evapotranspiration }}+H^{\text {Humidifying }}-H^{\text {Dehumidifiying }}-$

$H^{\text {Ventilation }}-H^{\text {Condensation }}$

Avec :

- $H^{\text {Evapotranpiration }}$ : vapour transferred from the ground to the indoor air by evapotranspiration $\left(g s^{-1}\right.$ of water).

- $H^{\text {Humidifying }}$ and $H^{\text {Déshumidification }}$ are, respectively, the humidifying and dehumidifying rates : $\left(g s^{-1}\right.$ of water).

- $H^{\text {Ventilation }}:$ water exchanged by ventilation $\left(g s^{-1}\right.$ of water).

- $H^{\text {Condensation }}:$ the water condensation process $\left(g s^{-1}\right.$ of water).

\section{B. Experimental Setup}

The agricultural greenhouse used has a transparent plastic cover (PVC), it is located north of Tunis with its axis parallel to the east-west direction. The process is surrounded by a 2.5 $\mathrm{m}$ high wind breeze to reduce the influence of the wind. The experimental device is $1.5 \mathrm{~m}$ long with a width of $1 \mathrm{~m}$ and a height of $1.15 \mathrm{~m}$ (Fig. 1) and is equipped with a data acquisition and processing system. A humidifier is placed inside the greenhouse. A dehumidifier type VERODRY 2009 LCD was also used; its role is to decrease the humidity level. A data acquisition system with several probes is used to measure different climatic parameters such as temperature, humidity, and solar radiation inside and outside the greenhouse; two sensors type LM35CZ are used to measure temperature, two sensors type SY-230 to measure relative humidity. The sensor's technical characteristics are listed in Table I [22,23,24]. The electronic components are protected by naturally ventilated boxes inside and outside the greenhouse (Fig. 2).

A thermopile cell type LPYRA03 is used to measure solar radiation. A data acquisition, processing, and control board type STM32F407VG Discovery is used to take measurements of different climatic parameters. The signals delivered by the sensors are amplified and conditioned using instrumentation amplifiers type AD620 before being transferred to the acquisition board (Fig. 3). The "STM Studio" software is used to process and transfer the data from the acquisition board to the computer; these data are measured every 30 seconds day and night then stored in files constituting a fairly large database of the greenhouse in different climatic conditions.

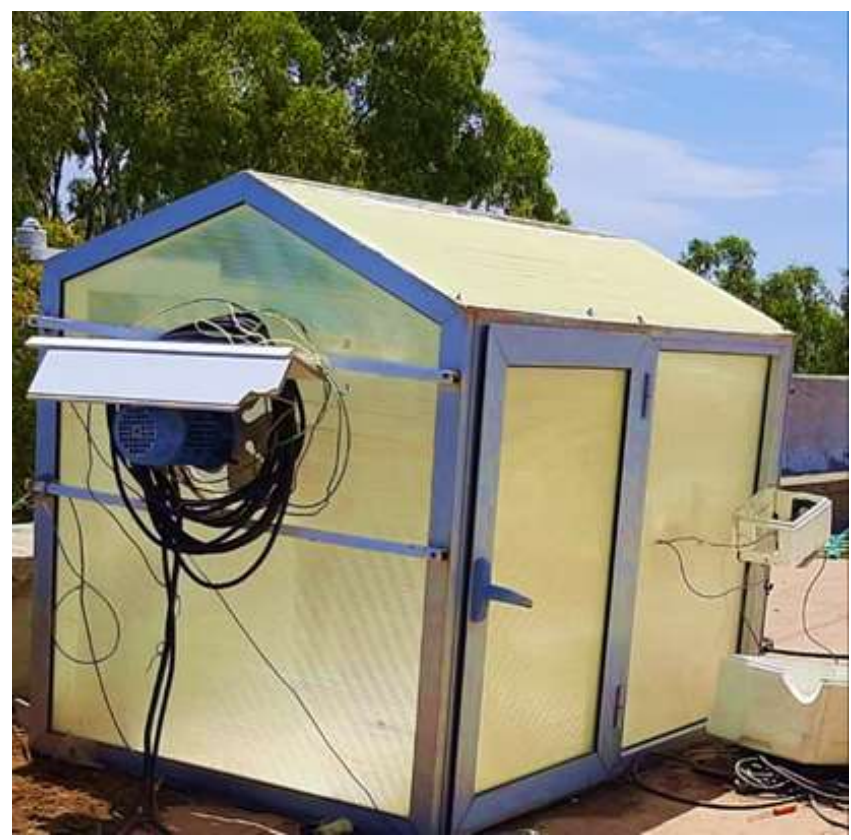

Fig. 1. Experimental Greenhouse.

TABLE I. SENSORS CHARACTERISTICS

\begin{tabular}{|c|c|c|c|}
\hline & $\begin{array}{l}\text { Temperature } \\
\text { sensor LM35 }\end{array}$ & $\begin{array}{l}\text { Humidity } \\
\text { sensor SY-230 }\end{array}$ & $\begin{array}{l}\text { Thermopile cell } \\
\text { LPYRA }\end{array}$ \\
\hline $\begin{array}{l}\text { Temperature } \\
\text { range }\end{array}$ & $\begin{array}{l}-55^{\circ} \mathrm{C} \text { to } \\
150^{\circ} \mathrm{C}\end{array}$ & & $-40^{\circ} \mathrm{C}$ to $80^{\circ} \mathrm{C}$ \\
\hline Rated voltage & 4 to 30 volt & $\begin{array}{l}\text { Dc } 5.0 \text { volt } \\
\text { nominal voltage }\end{array}$ & \\
\hline Rated power & $<60 \mu \mathrm{A}$ & $\begin{array}{l}\leq 3.0 \mathrm{~mA} \\
\text { Nominal power }\end{array}$ & \\
\hline $\begin{array}{l}\text { Operating } \\
\text { humidity }\end{array}$ & & $10-90 \% \mathrm{RH}$ & \\
\hline $\begin{array}{l}\text { Measuring } \\
\text { range }\end{array}$ & & & 0 to $2000 \mathrm{~W} / \mathrm{m}^{2}$ \\
\hline $\begin{array}{l}\text { Typical } \\
\text { sensitivity }\end{array}$ & & & $10 \mu \mathrm{V} /\left(\mathrm{W} / \mathrm{m}^{\wedge} 2\right)$ \\
\hline Impedance & $\begin{array}{l}\text { Low } \\
\text { impedance } \\
\text { output } 0.1 \Omega \\
\text { for } 1 \mathrm{~mA} \text { load } \\
\end{array}$ & & $33 \Omega$ to $45 \Omega$ \\
\hline Field of view & & & $2 \pi \mathrm{sr}$ \\
\hline Spectral field & & & $305 \mathrm{~nm}$ to $2800 \mathrm{~nm}$ \\
\hline
\end{tabular}

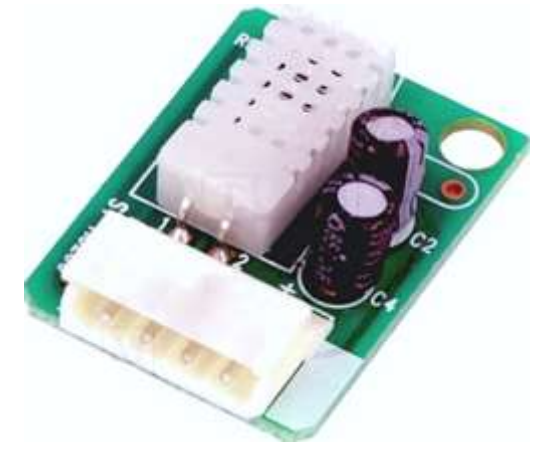

Fig. 2. Humidity Sensor. [25]. 


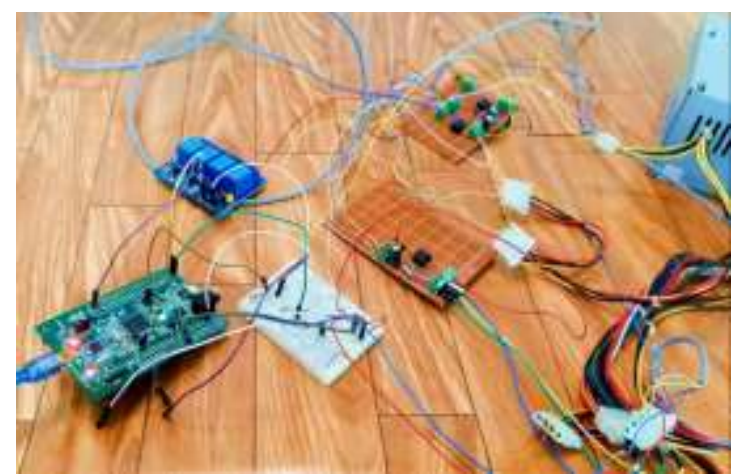

Fig. 3. Data Acquisition and Control Board.

\section{FUZZY CONTROL SCHEME}

\section{A. Fuzzy Logic Concept}

Climate regulation is of vital importance for the plant grown in the greenhouse. In this research work, a methodology based on fuzzy logic control is used. This particular technique is a valuable element in the control of systems whose parameters are subject to significant variations. Fuzzy logic control uses inferences with several rules linking input fuzzy variables to an output fuzzy variable so the fuzzy model is generally composed of fuzzification which involves a transformation of input variables into linguistic. Each input has its group of membership functions. The inference step consists of defining a logical relationship between the system inputs and outputs in the form of membership rules which can be drawn up in an inference table. The de-fuzzification step is the inverse of the fuzzification step, it allows to reconvert the fuzzy output into a net output (I can't find any other synonym for net) (Fig. 4).

\section{B. Humidity Fuzzy Control}

We have focused our study on indoor relative humidity control. This study is done because of the importance of humidity in greenhouse agricultural production. Humidity control was ensured by two actuators: the humidification system and the dehumidification system.

The fuzzy logic controller was developed to regulate the humidity inside the studied greenhouse where the included inputs are the error (between the set-point and the indoor humidity) and the previous control action of the actuators.

The linguistic terms used to describe the values of the inputs were negative (neg), null, positive (posi). The linguistic terms for the previous control action are dehumidification (dehumid), no_action and humidification (humid). The linguistic terms for the fuzzy control output are $\mathrm{mf} 1, \mathrm{mf} 2$ and $\mathrm{mf} 3$. The outputs are described by three levels where each one is associated to a different value; 1 is associated to the humidifier activation, the dehumidifier activation is associated to -1 and zero when both actuators are not activated. The same values are used in the input of the fuzzy controller since it represents the previous control action, (see Fig. 5, 6 and 7).

Initially, the inputs in each rule are fuzzified; their values are used as inputs of the membership functions belonging to each rule, the result are then used in a product method. The weight of each rule is obtained from each product.

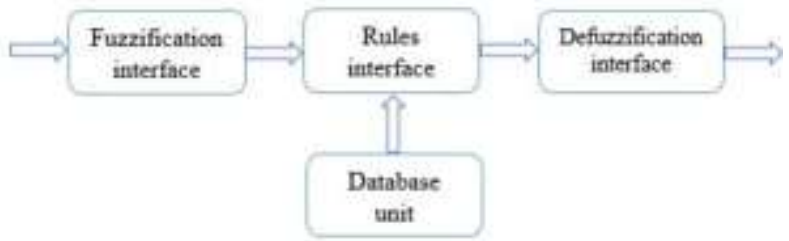

Fig. 4. Block Diagram of the Fuzzy Regulator.

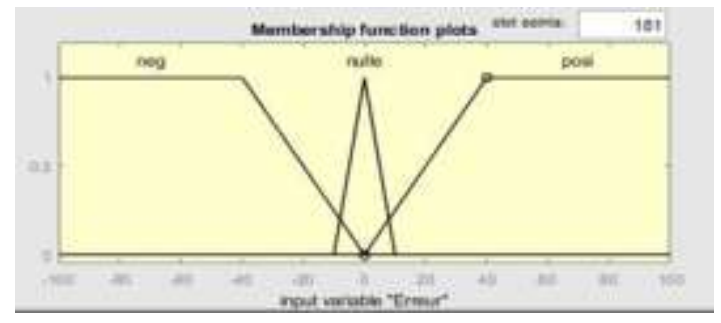

Fig. 5. Membership Functions of the Input Error.

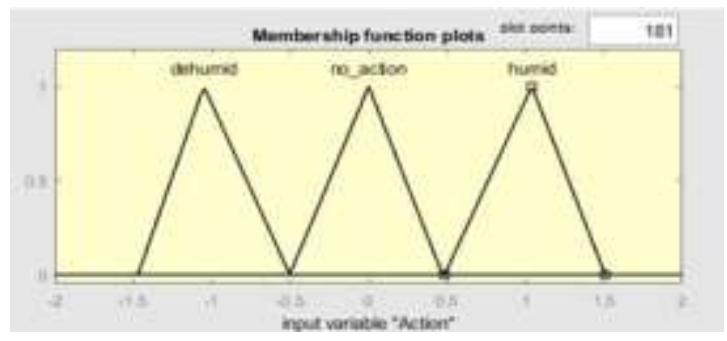

Fig. 6. Membership Functions of the Input Action.

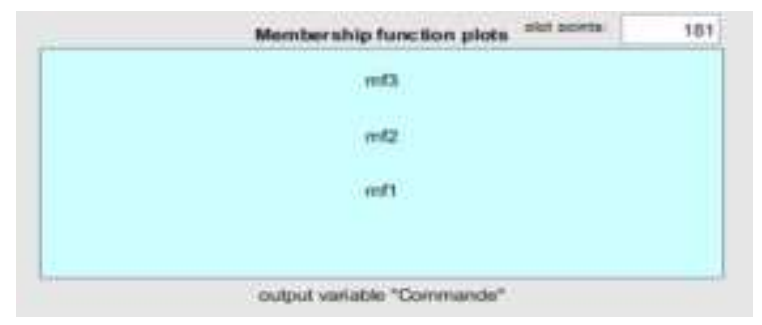

Fig. 7. Membership Functions of the Output.

It is worth noting that the defuzzification process is not applied here. That is deeply related to the On/Off activation way used by the actuators. Instead, the result of the inference process is used to determine the maximum weight between all the rules then apply the associated control output to the actuators (see Table II). The fuzzy controller uses nine rules.

TABLE II. FUZZY RULES OF THE RELATIVE HuMIDITY

\begin{tabular}{|l|l|l|}
\hline Error & Action & Command \\
\hline Humid & Posi & Mf3=1 \\
\hline Humid & Null & Mf3=1 \\
\hline Humid & Neg & Mf1= -1 \\
\hline No_action & Posi & Mf3=1 \\
\hline No_action & Null & Mf2=0 \\
\hline No_action & Neg & Mf3=1 \\
\hline Dehumid & Posi & Mf3=1 \\
\hline Dehumid & Null & Mf1 $=-1$ \\
\hline Dehumid & neg & Mf1 $=-1$ \\
\hline
\end{tabular}




\section{RESULTS AND DISCUSSION}

The samples used for climate control were taken from $14 / 10$ to $16 / 10$ at the LAPER laboratory. These measurements include solar radiation and humidity inside and outside the greenhouse.

Fig. 8 shows the solar radiation measured for about 46 hours, while the indoor and outdoor humidity is shown in Fig. 9 measured at the same time.

The responses of the two sensors (internal and external humidity) follow a periodic phenomenon of humidity variation and show almost identical evolutions with some differences. The external humidity depends on the solar radiation, for this reason, it increases during the night. Likewise, the indoor humidity increases during this period to approach that of the outside (and exceeds (80\%), and this excess requires the use of the dehumidifier to lower its value to a level suitable for the plant. On the contrary case, during the day the interior humidity decreases until it reaches its minimum value $(20 \%)$ that requires the use of a humidifier to increase the humidity.

The main objective of the control is to gently force the humidity inside the greenhouse to follow their desired trajectory. The response of the greenhouse interior humidity is shown in Fig. 10 for a period of 46 hours from 22/10 to 24/10 where the relative humidity set point was equal to $60 \%$. The activation of the humidification is associated to 1 , that of the dehumidification is associated to -1 and 0 describes the deactivation of the two actuators.

It can be seen that the humidity level during the day and night is maintained around its $60 \%$ set point except when the application time is between 22 and 24 hours. At that time, the humidification operates continuously but the humidity response cannot keep up. That can be explained by the high level of solar radiation reached in those moments. Apart from that period, one can observe that the dehumidifier system is more active in the night when the indoor humidity tends to surpass the set point. In the daytime, the humidifier system is more active or else the indoor humidity will decrease under the level of the set point.

The relative humidity evolution inside the studied greenhouse without and with the fuzzy controller is shown in Fig. 9 and 10, respectively. The fuzzy controller shows satisfactory results by better stability which proves the efficiency of this controller hence this study aimed to show the performance of FLC for setpoint monitoring and disturbance rejection.

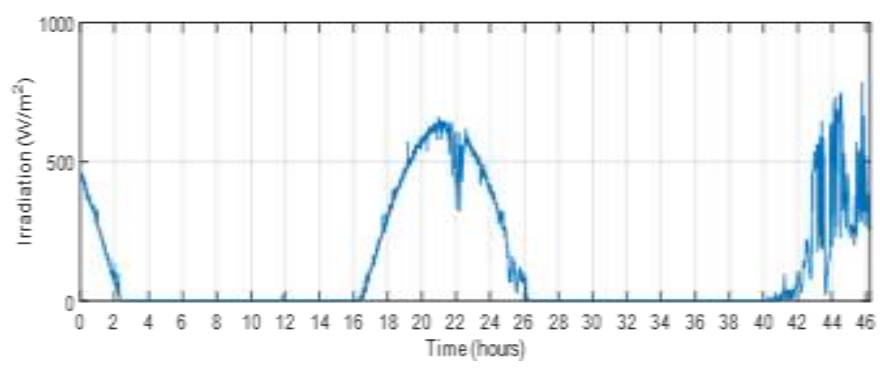

Fig. 8. Variation of the Intercepted Solar Radiation.

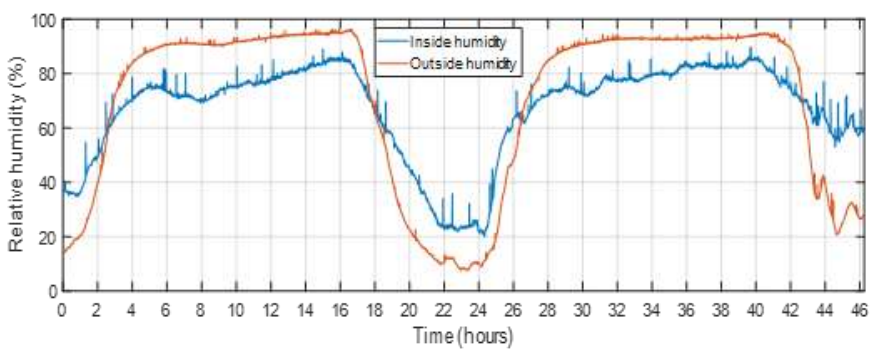

Fig. 9. Indoor and Outdoor Humidity Behavior without Control.

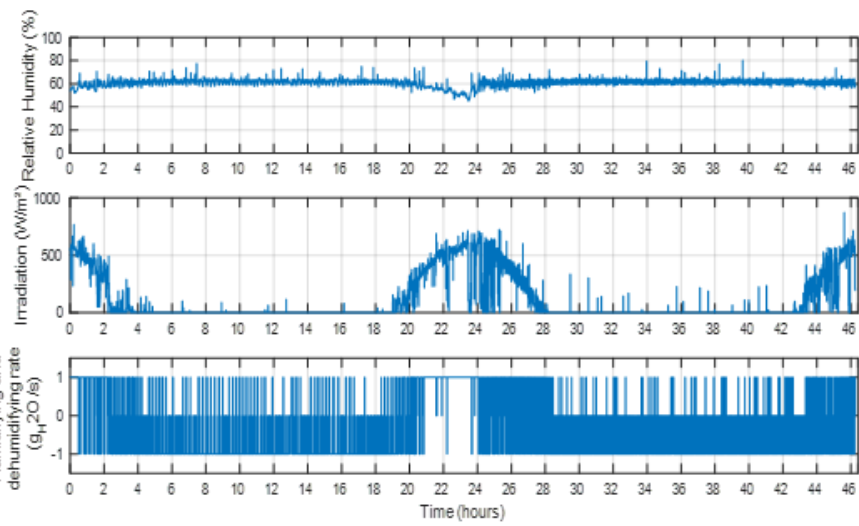

Fig. 10. The Variation of the Relative Humidity with the Controller FLC, the Irradiation Profile and the Humidifying/Dehumidifying Rate.

\section{CONCLUSION}

Climate management in greenhouses requires the choice of an automatic control system that is more reliable. In this article, we have developed a greenhouse environmental control system that manages the non-linearity of the system, using the fuzzy model for humidity control and real-time actuators that have been tested on a real greenhouse. This control strategy allows us to effectively regulate greenhouse humidity even in the presence of disturbances.

The simulation results show the performance and efficiency of the developed fuzzy logic control to manage the relative humidity inside the greenhouse in an efficient way. This controller ensures a careful follow-up of the predefined setpoint while reducing the operating time of the actuators.

\section{REFERENCES}

[1] A. Chouchaine, E. Feki, and A. Mami, "Stabilization using a discrete fuzzy PDC controlwith PID controllers and pole placement: application to an experimental greenhouse," J. Control Sci. Eng. pp. 1-9, 2011.

[2] F. Fourati, "Multiple neural control of a greenhouse, Neurocomputing," pp. 138-144, 2014

[3] M. Taki, Y. Ajabshirchi, S.F. Ranjbar, A. Rohani, and M. Matloobi, "Heat transfer and MLP neural network models to predict inside environment variables and energy lost in a semi-solar greenhouse, Energy Build.” pp. 314-329, 2016.

[4] A. Pawlowski, M. Beschi, J.L. Guzmán, A. Visioli, M. Berenguel, and S. Dormido, "Application of SSOD-PI and PI-SSOD event-based controllers to greenhouse climatic control," ISA Trans. Pp. 525-536, 2016.

[5] S. Mohamed, and I.A. Hameed, "A GA-based adaptive neuro-fuzzy controller for greenhouse climate control system,” Alex. Eng. J. 2016.

[6] B. Khoshnevisan, S. Rafiee, M. Omid, H. Mousazadeh, and S. Clark, "Environmental impact assessment of tomato and cucumber cultivation 
in greenhouses using life cycle assessment and adaptive neuro-fuzzy inference system," J. Clean. Prod. pp. 183-192, 2014.

[7] E. Lachouri, K. Mansouri, M. M. Lafifi, and A. Belmeguenai, "Adaptive neuro-fuzzy inference systems for modeling greenhouse climate," Vol. 7, University Badji Mokhtar Algeria, 2016.

[8] C. E. Lachouri, K. Mansouri, and A. Belmeguenai, "FPGA Implementation of Adaptive Neuro-Fuzzy Inference Systems Controller for Greenhouse Climate," Vol. 7, 2016.

[9] A. Hasni, R. Taibi, B. Draoui, and T. Boulard, "Optimization of greenhouse climate model parameters using particle swarm optimization and genetic algorithms," Energy Procedia 6, pp. 371-380, 2011.

[10] P.J.M. van Beveren, J. Bontsema, G. van Straten, and E.J. van Henten, "Optimal control of greenhouse climate using minimal energy and grower defined bounds," Appl. Energy, pp. 509-519, 2015.

[11] F. Hahn, "Fuzzy controller decreases tomato cracking in greenhouses." Comput. Elect. Agric. pp. 21-27, 2011.

[12] D.M. Atia, and H.T. El-madany, "Analysis and design of greenhouse temperature control usingadaptive neuro-fuzzy inference system," J. Electr. Syst. Inf. Technol. 2016.

[13] S. Revathi, and N. Sivakumaran, "Fuzzy based temperature control of greenhouse," IFACPap. OnLine 49, pp. 549-554, 2016.

[14] F. Hahn, "Irrigation fuzzy controller reduce tomato cracking." Universidad Autonoma Chapingo, México, 2011.

[15] F. Lafont and J.F. Balmat, "Optimized fuzzy control of a greenhouse, Fuzzy Sets Syst,” 128, pp. 47-59, 2002.

[16] M.A. Márquez-Vera, J.C. Ramos-Fernández, L.F. Cerecero-Natale, F. Lafont, J.- F. Balmat and J.I. Esparza-Villanueva, "Temperature control in a MISO greenhouse by inverting its fuzzy model," Comput. Electron. Agric. 124, pp. 168-174, 2016.
[17] P. Salgado and J.B. Cunha, "Greenhouse climate hierarchical fuzzy modelling, Control Eng," Pract. 13, pp. 613-628, 2005.

[18] M. Souissi,'Modelisation et commande du climat d'une agricole." Ph.D, these, chapter2, pp. 24-34, 2002.

[19] N. Atyah and H. Afif, "Modeling of greenhouse with PCM energy storage, energy convers.” Manag. 49, 3338-3342, 2008.

[20] P. Thirumal, K.S. Amirthagadeswaran and S. Jyabal, "Oprimization of IAQ characteristics of an air-conditioned car using GRA and RSM." J. Mech. Sci. Technol. 28, 1899-1907, 2014.

[21] S. Ashish and S. Tiwari, "Thermal modeling for greenhouse heating by using thermal curtain and earth-air heat exchanger." Build. Environ. 41, 843-850, 2006.

[22] T. H. Nasution and L. A. Harahap, "Predict the Percentage Error of LM35 Temperature Sensor Readings using Simple Linear Regression Analysis," 2020 4rd International Conference on Electrical, Telecommunication and Computer Engineering (ELTICOM), Medan, Indonesia, 2020, pp. 242-245, doi: 10.1109/ELTICOM50775.2020.9230472.

[23] M. Jomaa, F. Tadeo and A. Mami, "Modeling and experimental validation of the agricultural greenhouse," 2019 IEEE 19th Mediterranean Microwave Symposium (MMS), Hammamet, Tunisia, 2019, pp. 1-5, doi: 10.1109/MMS48040.2019.9157308.

[24] J. Yan, X. Liao, D. Yan and Y. Chen, "Review of Micro Thermoelectric Generator," in Journal of Microelectromechanical Systems, vol. 27, no. 1, pp. 1-18, Feb. 2018, doi: 10.1109/JMEMS.2017.2782748.

[25] N. Lekbangpong, J. Muangprathub, T. Srisawat and A. Wanichsombat, "Precise Automation and Analysis of Environmental Factor Effecting on Growth of St. John's Wort," in IEEE Access, vol. 7, pp. 112848-112858, 2019, doi: 10.1109/ACCESS.2019.2934743. 